\title{
KAJIAN PERANCANGAN PERANGKAP TURIS DENGAN PENGALAMAN BUDAYA BETAWI DI LENTENG AGUNG
}

\author{
Monica Vioni Leksono ${ }^{1)}$, Sutarki Sutisna2) \\ 1)Program Studi S1 Arsitektur, Fakultas Teknik, Universitas Tarumanagara, monicavioni@gmail.com \\ 2) Program Studi S1 Arsitektur, Fakultas Teknik, Universitas Tarumanagara, sutarkis@gmail.com
}

\begin{abstract}
Abstrak
Generasi millenial adalah generasi yang lebih suka mengeksplor hal baru dengan berwisata dibandingkan dengan menabung untuk kebutuhan masa depan. Generasi millenial lahir di era perkembangan teknologi yang pesat, membuat budaya asing masuk lebih mudah sehingga budaya lokal seperti budaya betawi kurang diminati oleh generasi ini. Kawasan Pariwisata di Jakarta Selatan yang kurang terpusat dan tidak memiliki konektivitas aktivitas yang kuat menyebabkan objek wisata kurang tereskplor, seperti Perkampungan Betawi di Setu Babakan. Penghubung antar objek wisata Ragunan dan Perkampungan Betawi dibutuhkan dengan membuat fasilitas dengan program edukasi dan hiburan yang bersifat informal yang dapat membantu wisatawan mempelajari lebih dalam mengenai budaya Betawi dengan pengalaman berlibur berdasarkan perilaku millenial. Perancangan ini disusun dengan mengkaji perilaku dari generasi millenial, perilakunya terhadap budaya Betawi dan karakteristik dari atraksi yang dapat menarik millenial untuk datang. Perangkap turis ini dirancang dengan strategi desain yang eksploratif, interaktif, dan menceritakan sebuah cerita dari pengalaman ruang sehingga dapat menarik perhatian millenial. Tapak yang berkontur dan jalur hijau yang berada di sepanjang tapak dan jalan membuat perangkap turis ini berintegrasi dengan ruang luar lebih baik. Metode naratif arsitektur diterapkan untuk membuat ruang kaya akan pengalaman imersif sehingga memiliki satu-kesatuan cerita. Para pengunjung dapat melakukan aktivitas yang menyenangkan dengan belajar menggunakan media digital interaktif dalam bentuk galeri kuliner, area belajar mandiri, pelatihan ketrampilan dan permainan yang didasari oleh cerita sejarah budaya betawi dan cerita rakyat betawi.
\end{abstract}

Kata kunci: betawi; budaya; millennial; pariwisata; perangkap

\begin{abstract}
Millennials is a generation who prefers exploring new things rather than saving for future. Millennials who were born in rapid high technology development era make the global culture affects the generation easily, this causes the local culture such as betawi culture is less demanded by millennials. Tourism area in South Jakarta which less centralized and not having strong activity connection make some of the attractions unexplored, such as Betawi Village in Setu Babakan. A connector between Ragunan attractions \& Perkampungan Betawi in Setu Babakan is needed by creating facilities with informal education and entertainment program that can help tourist to explore more about betawi culture with holiday experience. This design is studied by researching the behavior of Millennials, their behavior towards betawi culture and the characteristics of attractions that will be able to make Millennials come. The design strategy of this touris trap is explorative, interactive, and telling a story about a space experience that can catch Millennials' attention which can be adapted to their behavior. Contoured site and green area along the site and street make this tourist trap integrated well with green area. Narrative architecture method is applied to make space rich with immersive experience in order to have their one story. Visitors can do fun activities by learning with interactive digital media in the form of cullinary gallery, self learning area, workshop, and escape room based on betawi culture history and the story of Betawi folkfore.
\end{abstract}

Keywords: behavior; betawi; culture; millennial, tourism 


\section{PENDAHULUAN}

Generasi millenial adalah generasi yang lebih suka memiliki pengalaman dengan traveling dibandingkan dengan memiliki aset atau menabung untuk membeli rumah. Generasi millenial mencari pengalaman dengan event, dining, dan terutama traveling (rangkuman dari beberapa sumber artikel). Wisatawan millenial diprediksi akan mendominasi pariwisata sebesar 57 persen pada tahun 2030 , oleh sebab itu wisatawan millenial sangat berpengaruh kepada industri pariwisata.

Pariwisata adalah sektor yang menjadi penyumbang devisa terbesar kedua di Indonesia pada tahun 2018 dan diprediksi akan menjadi penyumbang devisa terbesar di tahun 2019. Jakarta selain menjadi pusat pemerintah, juga merupakan pusat bisnis dan pusat kebudayaan serta memiliki yang diunggulkan, salah satunya adalah Kebun Binatang Ragunan. Ragunan memiliki potensi untuk menjadi pemicu kawasan pariwisata di Jakarta Selatan dengan jumlah pengunjung yang dapat mencapai 200.000 pada hari libur tertentu (Desember 2018). Selain Ragunan, dalam radius $5 \mathrm{~km}$ terdapat Setu Babakan dan Kampung Betawi yang mempunyai ciri khas kebudayaan lokal Jakarta yang diresmikan pada tahun 2001 dengan jumlah pengunjung yang dapat mencapai 10.000 pada hari libur (Desember 2018). Perbedaan jumlah pengunjung sampai 20 kali lipat menunjukkan bahwa wisatawan tidak tersalurkan dengan baik dan Kampung Betawi merupakan objek wisata yang tidak tereksplor sehingga dapat dinyatakan bahwa kawasan pariwisata di Jakarta Selatan kurang terhubung satu sama lain.

Teknologi dan globalisasi menyebabkan budaya betawi ini akan menghilang karena minat dari generasi millenial sebagai generasi penerus semakin menurun. Hal ini menyebabkan krisis identitas dan lokalitas yang menjadi permasalahan. Perlu adanya suatu "perangkap" yang dapat menarik wisatawan millenial untuk datang dan mengenal budaya betawi yang didasari oleh perilaku millenial. Perilaku millenial yang eksploratif menyebabkan muculnya edutaintment dimana edukasi dan entertainment dapat menjadi satu dimana millenial dapat tetap berwisata dan belajar disaat yang sama. Pembelajaran budaya betawi tersebut akan ditangkap pengunjung dengan pengalaman liburan.

Berdasarkan isu yang sudah diuraikan, maka dibutuhkan suatu wadah atau fasilitas penghubung yang mampu menjadi ruang sebagai titik temu dan penyalur wisatawan millenial yaitu berupa tourist trap dengan pengalaman budaya betawi untuk mengenalkan budaya betawi serta menyalurkan wisatawan ke Kampung Betawi.

\section{KAJIAN LITERATUR}

\section{Generasi Millenial}

Generasi Millenial adalah generasi yang lahir pada tahun 1980 sampai dengan 2000 dan dapat juga disebut dengan generasi $Y$. Generasi ini berada diantara generasi $X$ yang lahir pada tahun 1965 sampai dengan 1980 dan generasi Z yang lahir setelah tahun 2000. (Purwadi, 2016: 13)

\section{Perilaku Millenial}

Perilaku Millenial berbeda dibandingkan dengan generasi sebelumnya, berikut ini adalah karakteristik dan perilaku dari generasi millenial yang dapat mempengaruhi dalam membentuk pengalaman dan karakter ruang 


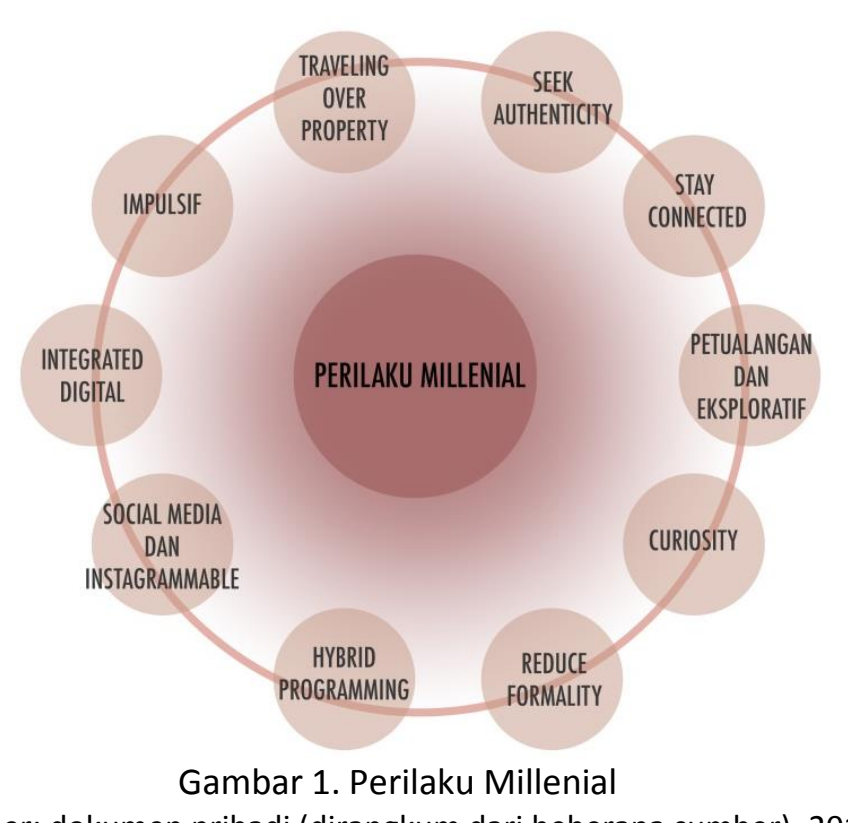

Sumber: dokumen pribadi (dirangkum dari beberapa sumber), 2019

a. Suka berpetualang dan eksploratif, wisatawan millenial suka mengekslor suatu tempat, sehingga mereka mendapatkan pengalaman yang lebih dibandingkan hanya berelaksasi.

b. Social media dan instagrammable, dengan adanya spot berfoto untuk dapat dibagikan melalui media sosial mengenai identitas keberadaan mereka di suatu tempat.

c. Tidak suka hal-hal formal, generasi millenial adalah generasi yang bersifat fleksibel dimana mereka merupakan generasi multitasking. Sehingga program yang diberikan merupakan program hybrid dimana pengunjung dibawa untuk belajar dengan pengalaman berlibur yang disebut dengan edutatinment yang merupakan gabungan dari edukasi dan entertainment.

\section{Perilaku Millenial terhadap budaya}

Pandangan dan perilaku millenial terhadap budaya kurang bisa dirasakan dengan adanya era globalisasi ini. Budaya asing yang masuk dengan sangat mudah oleh teknologi yang canggih membuat budaya lokal tidak terlestarikan lagi oleh generasi millenial.

\section{Taman tematik}

Theme Park adalah istilah untuk sekelompok atraksi hiburan dan wahana dan acara lainnya di suatu lokasi untuk dinikmati sejumlah besar orang. Theme Park lebih rumit daripada sebuah taman kota atau taman bermain yang sederhana, biasanya menyediakan tempat dimaksudkan untuk melayani anak-anak, remaja, dan orang dewasa. Theme Park adalah sebuah taman hiburan yang dekoratif dan dirancang untuk mencerminkan satu tema tertentu sebagai tema utama, seperti suatu periode khusus dalam suatu cerita atau dunia di masa yang akan datang (Webster 2010).

\section{Karakteristik Taman Tematik}

Dalam bukunya yang berjudul Theme Park, Scoot A. Lucas mengungkapkan bahwa taman bertema memiliki 6 karakteristik yaitu sebagai berikut :

a. Theme park as oasis (sebagai sumber ketenangan)

b. Theme park as land (sebagai dunia impian)

c. Theme park as machine (sebagai mesin wahana

d. Theme park as show (sebagai pertunjukan)

e. Theme park as brand (sebagai merk)

f. Theme park as text (sebagai bacaan/cerita) 
Terdapat dua contoh alur yang dapat diterapkan dalam theme parks, yaitu thoroughfare movement dan loop movement yang digambarkan dalam ilustrasi berikut

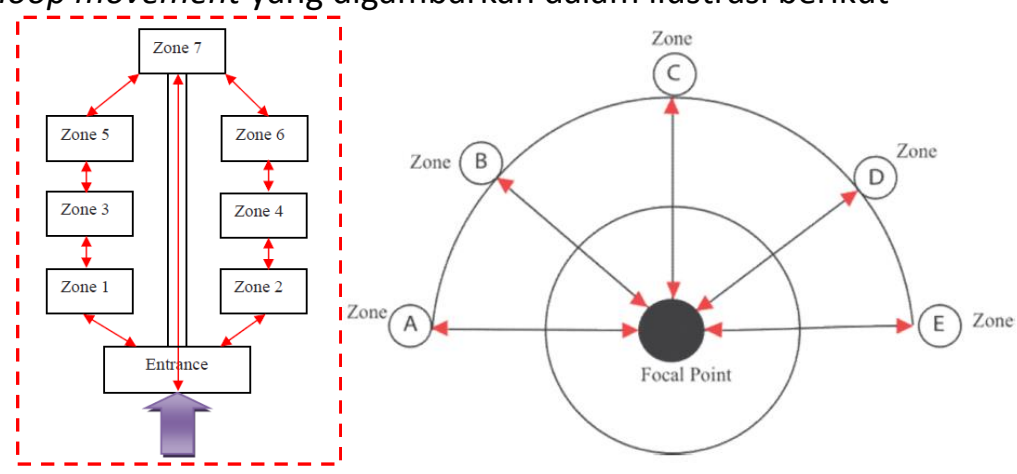

Gambar 2. Contoh ilustrasi dari thoroughfare movement dan loop movement

Sumber: Effectiveness of Wayfinding Towards Spatial Space and Human Behavior in Theme Park. Jurnal. 2013

Alur yang diterapkan ada perancangan ini adalah thoroughfare movement dikarenakan alur yang diterapkan lebih jelas dan terarah sehingga pengalaman ruang dapat menjadi lebih bermakna dan memiliki urutan cerita.

\section{Tipologi atraksi}

Berdasarkan pengelompokkan jenis atraksi, tourist trap digolongkan menjadi atraksi kultural kareana ingin menyampaikan nilai-nilai budaya dari betawi. Program-program yang termasuk dalam pengelompokkan tersebut adalah tapak bersejarah, museum, teater, dan ruang arsitektur di dalamnya.

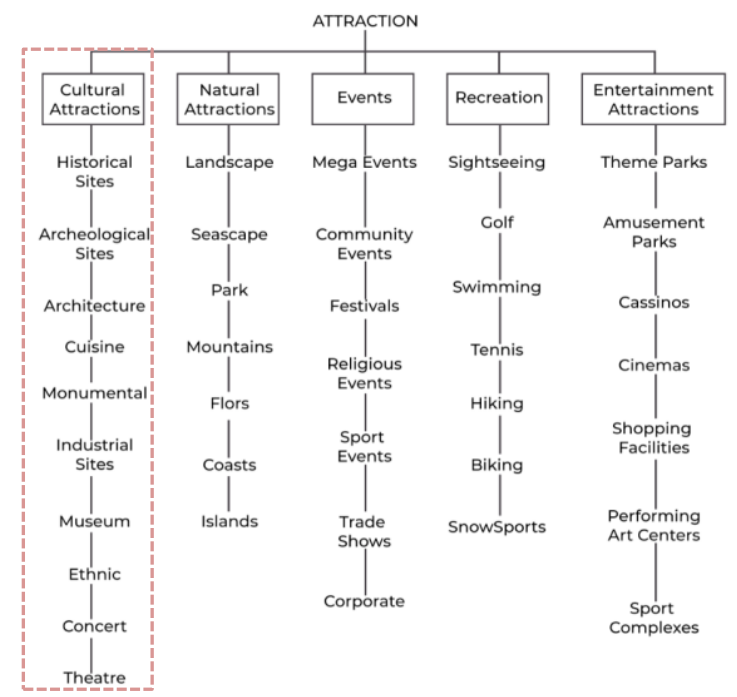

Gambar 3. Tipologi Atraksi

Sumber: Digambar ulang menurut edb.gov.hk, 2019

\section{METODE}

Metode penelitian yang digunakan adalah design by research. Metode ini dilakukan dengan pembuatan kuisioner terkait keminatan generasi millenial terhadap theme parks. Selain itu, pengumpulan beberapa riset mengenai perilaku-perilaku millenial dan teori yang mempengaruhi keruangan dari arsitektur yang dapat diaplikasikan dalam desain.

Metode perancangan yang digunakan adalah metode narasi oleh Nigel Coates. Metode ini digunakan untuk dapat memberikan makna atau arti lebih dalam pengalaman ruang agar lebih imersif. Perancangan didasari oleh cerita dari sejarah terbentuknya betawi, cerita legenda dari Si Pitung yang diterapkan ke dalam program dan konten dan membentuk suatu ruang dengan media-media seperti LED panel. 


\section{METODE PERANCANGAN}

NARRATIVE ARCHITECTURE (PENDEKATARAN NARATIF)

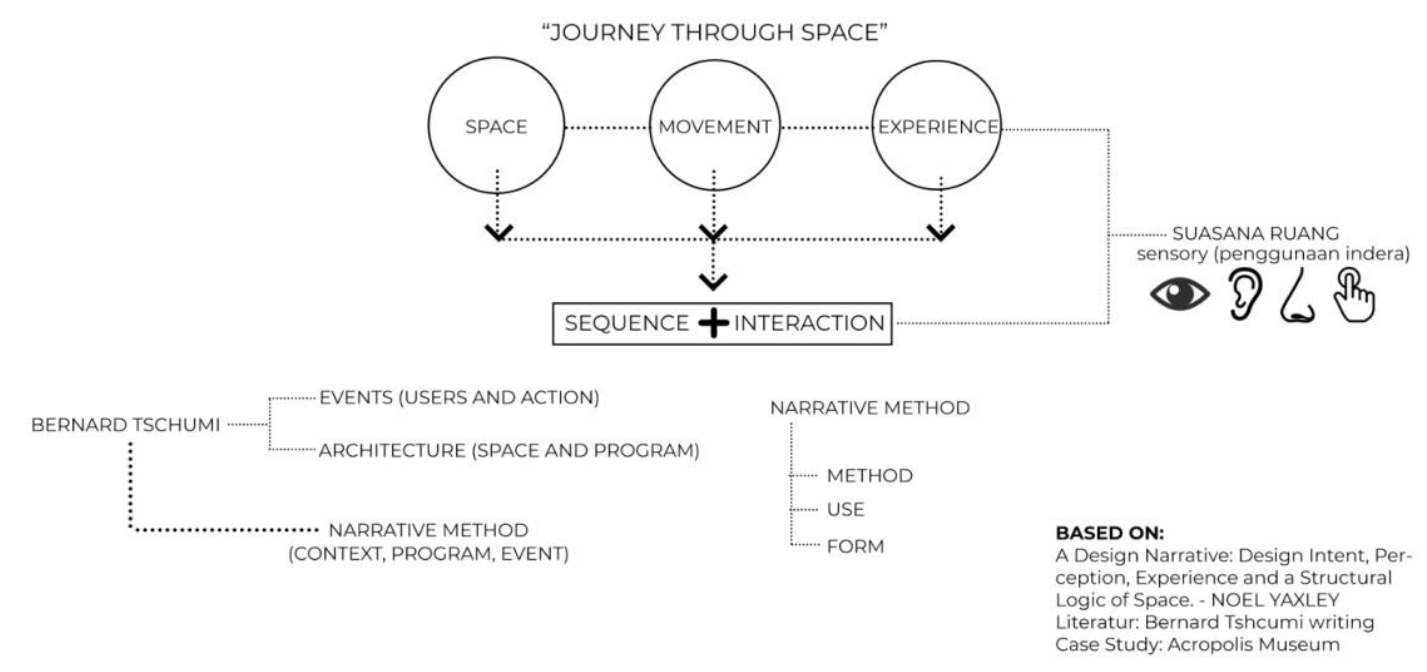

Gambar 4. Metode Perancangan Pendekatan Naratif

Sumber: Dokumen Pribadi, Rangkuman dari A Design Narrative oleh Noel Yaxley

Cerita dari sejarah betawi diaplikasikan dengan media pameran layar interaktif, infinity room, dan ruang hologram. Pada ruang pameran interaktif dengan media LED panel yang terdapat pada dinding dan lantai membuat para pengujung merasakan situs sejarah dari betawi yang berasal dari jaman kerajaan. Pada zona permainan yaitu escape room, pengunjung diajak untuk menjadi bagian dari cerita Si Pitung.

Metode lain yang digunakan adalah pendekatan neovernakular pada bangunan. Arsitektur neovernakular adalah aliran yang berkembang pada era post modern. Aliran ini disebakan oleh adanya protes para arsitek terhadap pola-poa yang berkesan monoton. Prinsip-prinsip neovernakular yang diterapkan pada bangunan adalah hubungan langsung, hubungan lansekap, hubungan kontemporer. Hubungan langsung digambarkan dengan penggunaan atap betawi pada bangunan dan bentuk elemen dari rumah kebaya pada dinding gate dan dinding pembentuk ruang.

\section{DISKUSI DAN HASIL}

Perancangan gubahan massa didasari dengan adanya tema yaitu trap dan perpaduan antara ide dan analisis lingkungan tapak sekitar. Keseluruhan konsep dari perancangan ini adalah

a. Trap: dimana millenial diajak untuk masuk ke dalam proyek dan mempelajari lebih dalam mengenai budaya betawi dan penerapan konsep bangunan: entrance - trap - release. Dimana pengunjung diundang masuk melalui jembatan penyeberangan lalu masuk bermain dan belajar kemudian melepas semua suasana dengan suasana outdoor yang berorientasi ke ruang publik kota. 


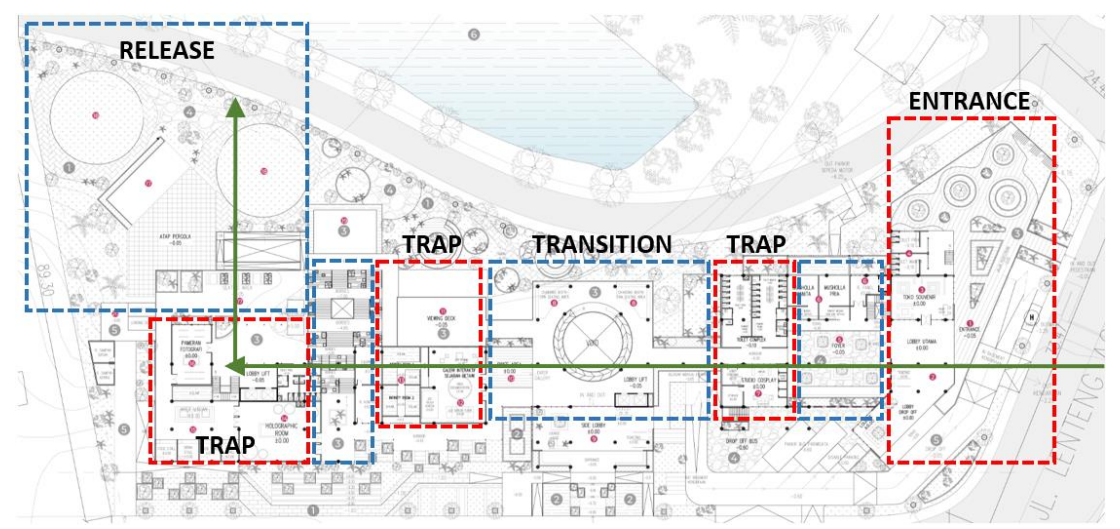

Gambar 5. Konsep Trap dalam Perancangan

Sumber: Penulis, 2019

b. Betawi: dengan konten pembelajaran budaya-budaya betawi mulai dari kesenian hingga workshop ondel-ondel mini. Pengunjung diajak untuk menjadi suatu bagian dari kegiatan aktivitas itu masing-masing sehingga lebih interaktif dan lebih atraktif bagi millenial.

c. Experience: dengan ikut unjuk dalam kegiatan masing-masing galeri seperti escape room yang masuk ke dalam suatu cerita dari si Pitung itu sendiri dan bermain serta berperan sebagai salah satu tokoh.

\section{KONSEP TRAP}

MENARIK PERHATIAN MILLENIAL DAN MEMPERKENALKAN KEMBALI BUDAYA BETAWI DENGAN CARA MILLENIAL.

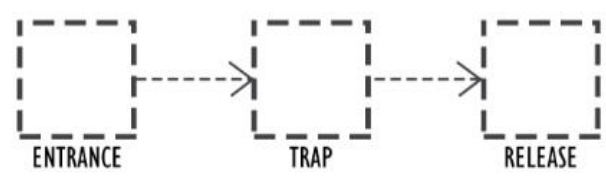

PENGUNJUNG DIBAWA UNTUK MASUK MELALUI ENTRANCE DAN MASUK KE DALAM RUANG YANG BERUPA GALERI, PERMAINAN. LALU MERELEASE SEMUA HAL TERSEBUT DENGAN RUANG TERBUKA HIJAU YANG ADA DI BAGIAN PALING DALAM TAPAK YANG BERINTEGRASI DENGAN RUANG PUBLIK

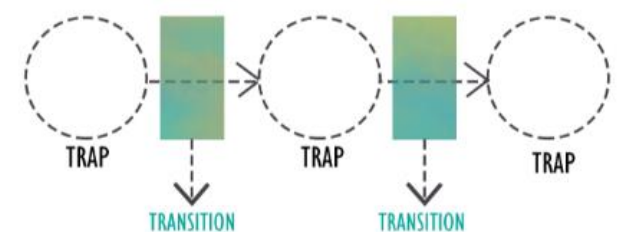

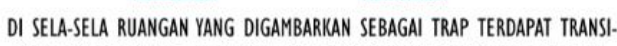
TION BERUPA RUANG LUAR YANG MEMPERTEMUKAN PENGUNJUNG DENGAN ELEMEN ALAM SEPERTI HIJAU DAN AIR

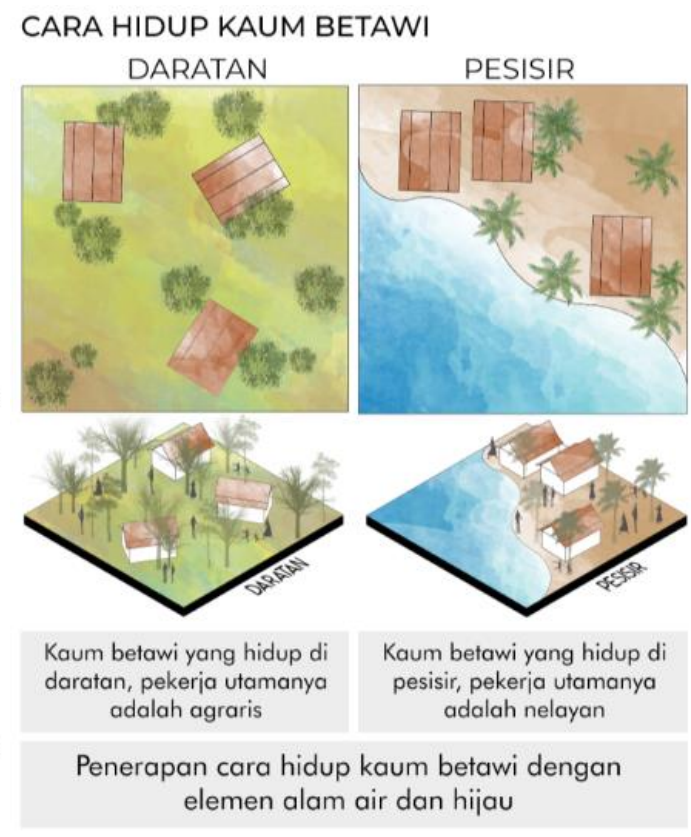

Gambar 6. Konsep Perancangan

Sumber: Penulis, 2019

Gubahan massa diambil dari tema trap yang diaplikasikan ke dalam tapak melalui konsep entrance - trap - release dengan memperhitungkan kondisi tapak. Di antar trap tersebut juga ada transisi dari kejenuhan, dimana zona permainan ada. Selain itu, konsep lansekap yang diambil dari pola perkampungan betawi yang dibedakan berdasarkan tempat tinggal di pesisir dan daratan. Entrance yang diterapkan dengan adanya lobby dan jalur masuk yang berintegrasi dengan jembatan penyeberangan yang ada di Jl. Lenteng Raya Agung dan disambut dengan lobby serta hallnya. Selain itu transition ini merupakan rancangan dimana setelah pengunjung keluar dari suatu zona, pengunjung akan bertemu dengan ruang luar dan elemen seperti hijau dan air. Elemen hijau diletakkan pada area-area perkarangan di depan zona-zona program utama, sedangkan elemen air diterapkan pada sirkulasi seperti selasar atau koridor. 


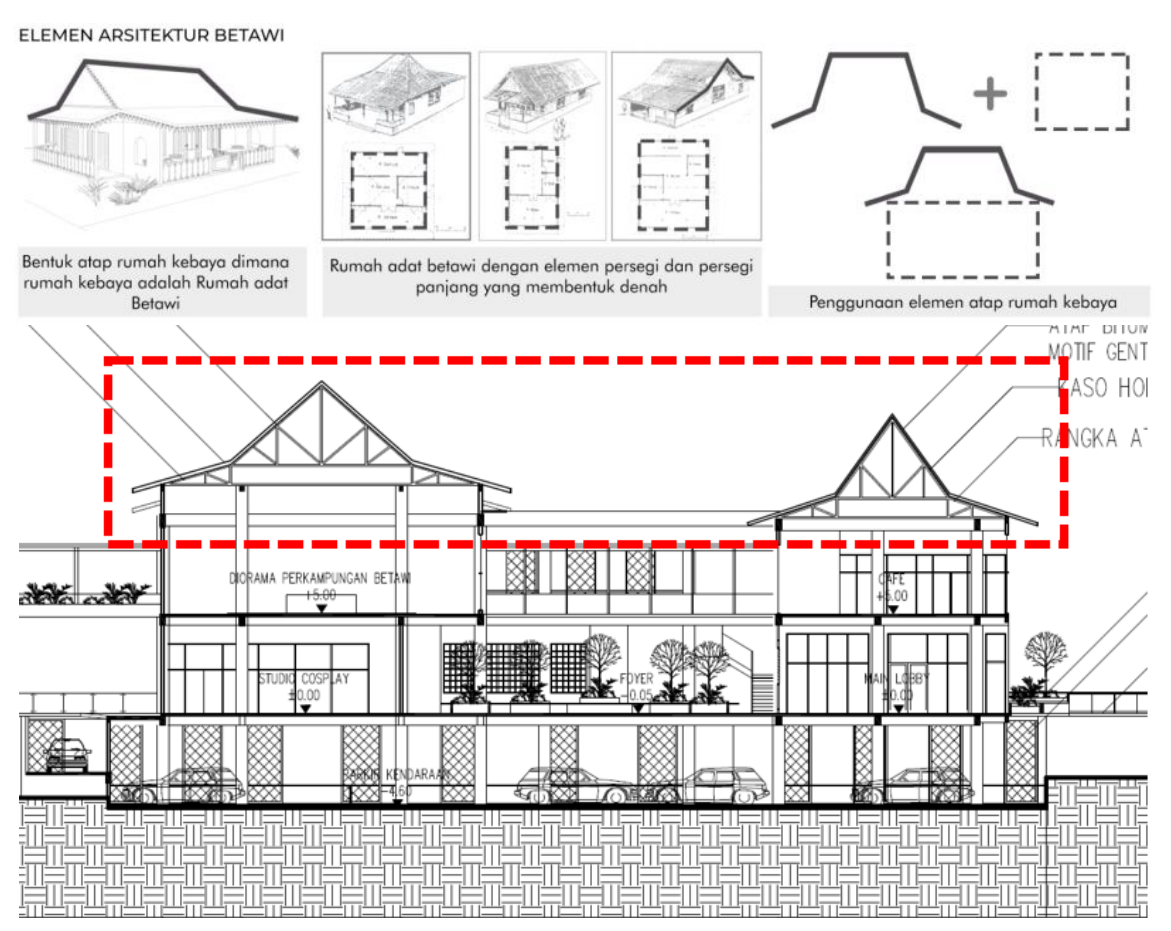

Gambar 7. Elemen Arsitektur Betawi dan Aplikasi pada Perancangan Sumber: Penulis, 2019

Penerapan pendekatan neovernakular dengan adanya elemen-elemen yang membentuk ruang dan penggunaan atap rumah kebaya pada massa di bagian timur dan barat. Pendekatan ini diharapkan untuk dapat masih memberikan identitas arsitektur budaya betawi dalam bentuk yang modern dan menyamakan dengan jaman millenial. Dengan adanya penerapan neovernakular maka arsitektur betawi masih dapat diterapkan akan tetapi millenial yang lebih suka untuk kearah modern juga tidak hilang dari perancangan.

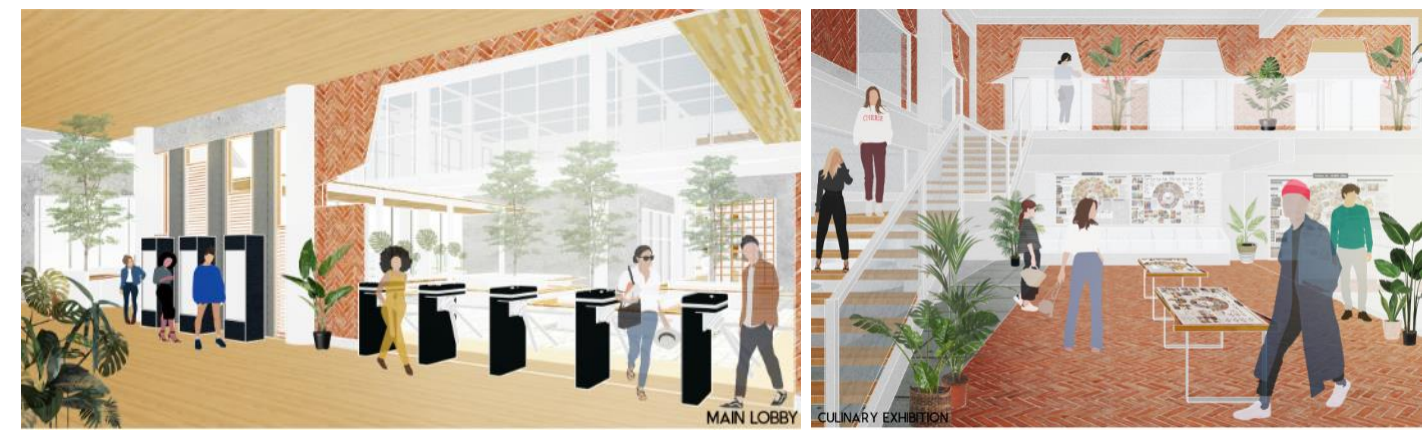

Gambar 8. Interior Lobby dan Galeri Kuliner Sumber: Penulis, 2019

Pendekatan arsitektur neovernakular tidak hanya dari atap, akan tetapi dilakukan transformasi dari tampak rumah kebaya tersebut lalu dijadikan efek negative space dan membentuk suatu icon yang diterapkan pada interior. Penerapan elemen arsitektur budaya betawi dapat dilihat melalui interior lobby utama dan galeri kuliner. Dimana pada lobby utama elemen tersebut diterapkan sebagai gate. Sedangkan pada galeri kuliner diterapkan sebagai dinding pembentuk ruang. Perancangan ini diupayakan tidak hanya secara konten betawi itu ada akan tetapi beberapa bentukan ciri khas betawi terdapat pada ruang. Penggunaan elemen seperti bata tempel dan kayu juga memberikan efek tradisional yang khas, dikarenakan arsitetur betawi yang banyak menggunakan kayu dan kisi-kisi sebagai material bangunan dan elemen ciri khas rumah-rumah adatnya. 


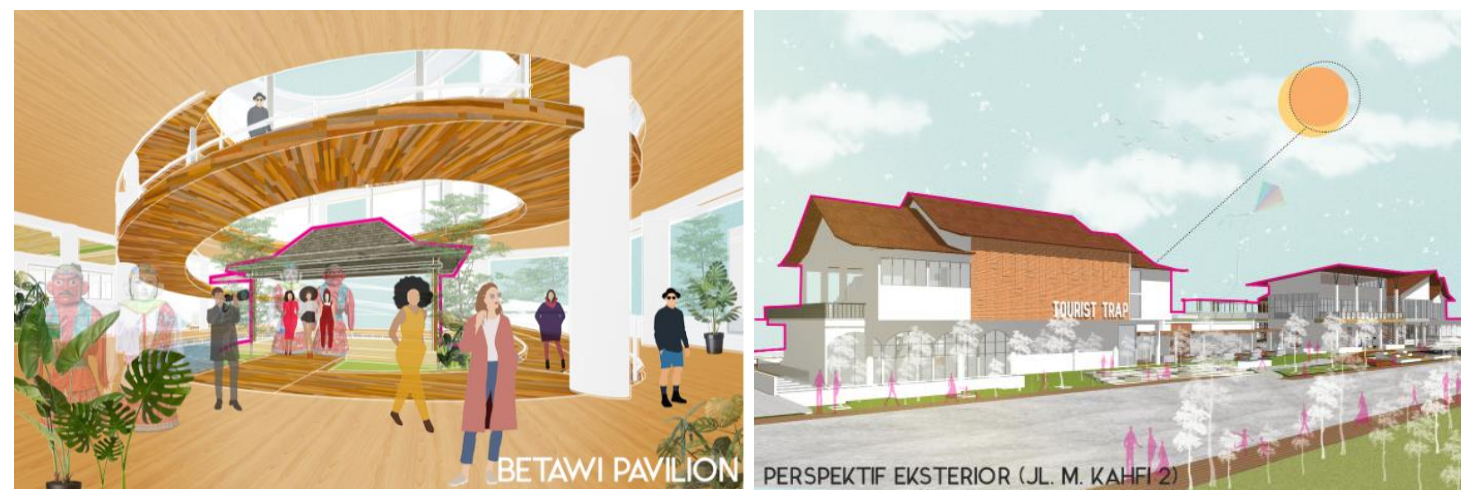

Gambar 9. Pavilion Betawi dan Eksterior

Sumber: Penulis, 2019

Pada massa bagian tengah yang didominasi oleh ruang terbuka dan sirkulasi vertikal berupa ramp. Terdapat pavilion betawi yang dapat menjadi spot foto menarik, dirancang dengan void dengan tujuan cahaya dapat fokus untuk menerangi pavilion betawi pada siang hari dan diletakkan di lantai paling bawah untuk dapat dilihat dari semua lantai dan awal entrance.

Penerapan atap rumah kebaya pada eksterior. Warna yang digunakan juga merupakan warna-warna yang memberikan nuansa modern dan tradisional, yaitu dengan penggunaan warna putih dan cokelat. Penggunaan kisi-kisi kayu sebagai dekorasi pada viewing deck juga dapat menjadi spot foto yang menarik bagi para millenial.

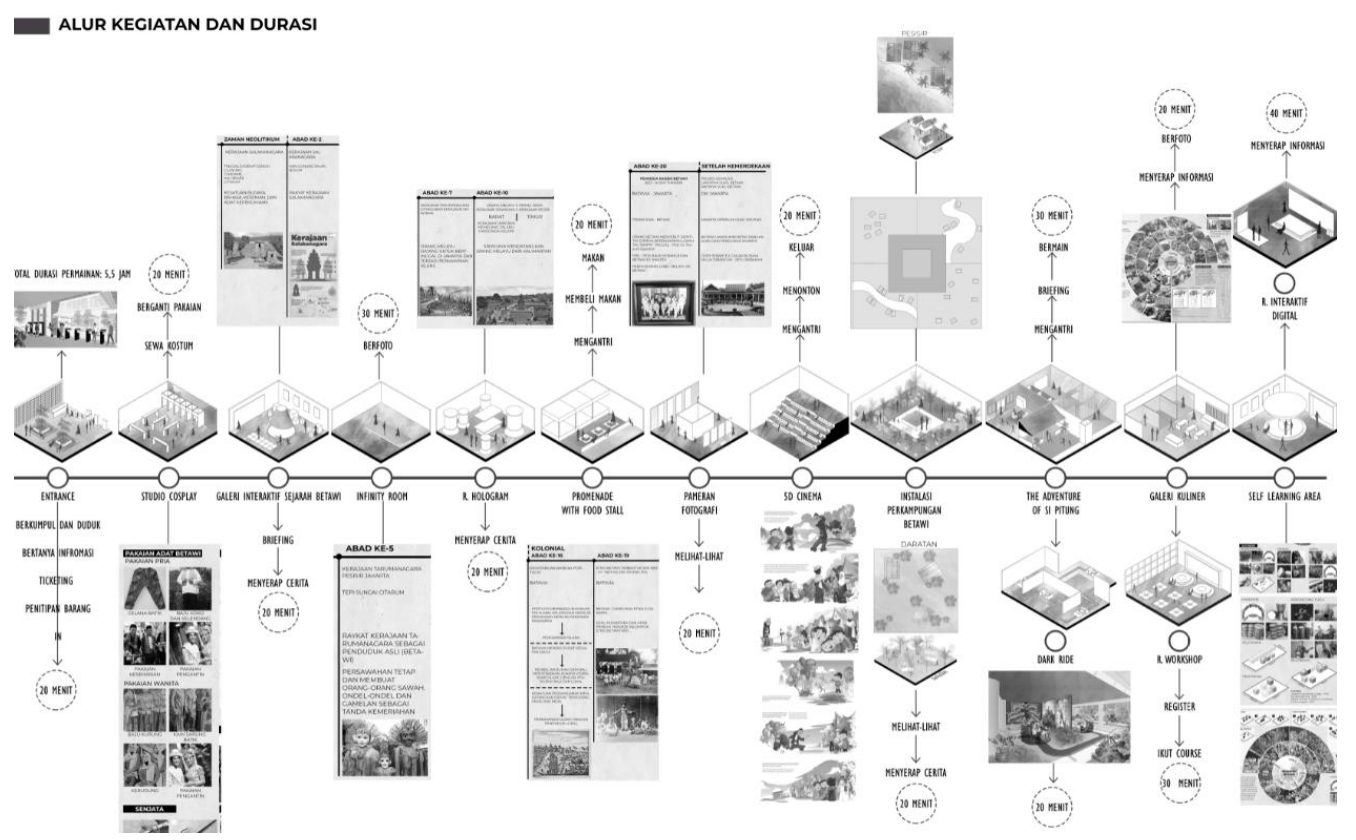

Gambar 10. Alur kegiatan dan Durasi

Sumber: Penulis, 2019

Durasi permainan dalam perancangan ini berkisar 5 jam dan dapat dilaksanakan dalam sistem one day trip. Penerapan jenis perjalanan ini adalah berfungsi untuk membuat objek wisata yang ada disekitar seperti Ragunan dan Kampung Betawi untuk semakin berkembang. Dengan adanya banyak objek wisata yang menggunakan sistem one day trip, maka permainan yaang berdekatan dant tidak dapat diselesaikan dalam sehari membuat potensi perkembangan sektor wisata lainnya seperti akomodasi dan fasilitas kebutuhan lainnya. 
Alur dari perancangan diatur mulai dari lobby kemudian pengunjung dibawa masuk untuk dapat memahami dahulu sejarah terbentuknya budaya betawi dengan ruang-ruang interaktif dan spot foto. Ruang-ruang tersebut juga dilengkapi dengan musik yang sesuai dengan karakter ruang dan suasana sehingga pengalaman yang ada lebih dapat dirasakan bukan hanya dari indera penglihatan dan peraba tetapi pendengaran. Kemudian pengunjung diajak untuk menikmati 5D Cinema yang menceritakan cerita rakyat dari Si Pitung.

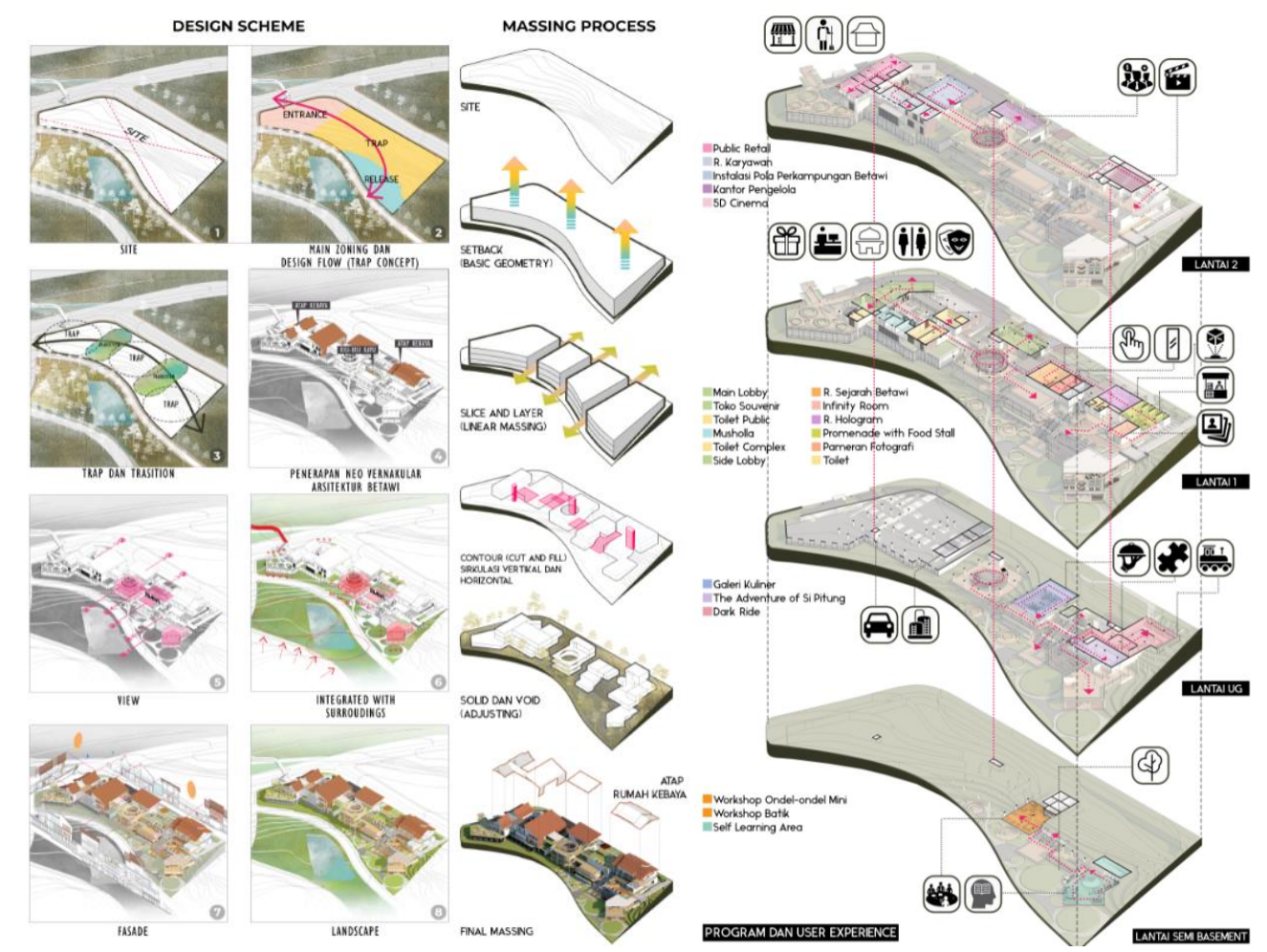

Gambar 11. Langkah Proses Gubahan dan Program Sumber: Penulis, 2019

Proses gubahan massa, didapatkan dari penggabungan tema, konsep, ide, dan hasil dari analisis tapak. Proses dimulai dengan konsep entrance-trap-release yang digambarkan oleh pintu masuk, program utama, dan ruang komunal dalam bentuk green landscape. Tapak memiliki topografi atau kontur setinggi $10 \mathrm{~m}$ dari sisi tenggara tapak sampai sisi barat laut tapak. Lalu kemudian dengan transisi dari dari masing-masing perhitungan kejenuhan trap tersebut berupa area makan yang berbentuk food dan drink stall dimana pengunjung dapat duduk dan menikmati makanan dan minumannya. Lalu dengan adanya integrasi dengan sekitar dan view makan dirancang sebuah viewing deck dan bentukan massa pun trap dengan balkon-balkon yang dimanfaatkan sebagai rooftop garden.

Pada lantai pertama, terdapat lobby, dan zona sejarah dari betawi. Pengunjung diharapkan untuk dapat mengetahui sejarah dari terbentuknya betawi terlebih dahulu. Lalu kemudian pengunjung dibawa untuk merasakan sebuah arena 5D Cinema yang menceritakan mengenai cuplikan perjalanan dari Si Pitung yang berada di lantai 2. Pada lantai 2 juga terdapat pembelajaran mengenai perkampungan betawi yang diterapkan dalam instalasi dan diorama dalam ruang. Pada lantai UG terdapat permainan The Adventure of Si Pitung dimana berupa escape room dan dark ride yang dapat menjadi jeda dari pengunjung dalam menikmati informasi dari budaya betawi. Pada bagian lantai semi basement terdapat ruang workshop ondel-ondel mini dan membatik dengan sifat ruang semi outdoor tanpa dinding pembatas dan berhadapan langsung dengan ruang luar dan ruang publik yang ada di utara bangunan. Selain itu, juga ada ruang self-learning area dimana pengunjung dapat memperlajari sendiri 
mengenai kesenian-kesenian dari budaya betawi yang diterapkan melalui instalasi display dan ruang interaktif. Ruang interaktif ini mempunyai LED projector dan scanner. Para pengujung dapat menggambarkan apa yang ia ketahui tentang betawi dan meng-scan gambar tersebut dan dimasukkan ke dalam layar tampilan, sehingga pameran dari seni tersebut memiliki interaksi dengan pegunjung.

Selain itu, seperti yang sudah dibahas di konsep keseluruhan dari perancangan, dimana terdapat area release yang dirancang dengan landscape dimana ruang terbuka ini difungsikan sebagai ruang komunal.

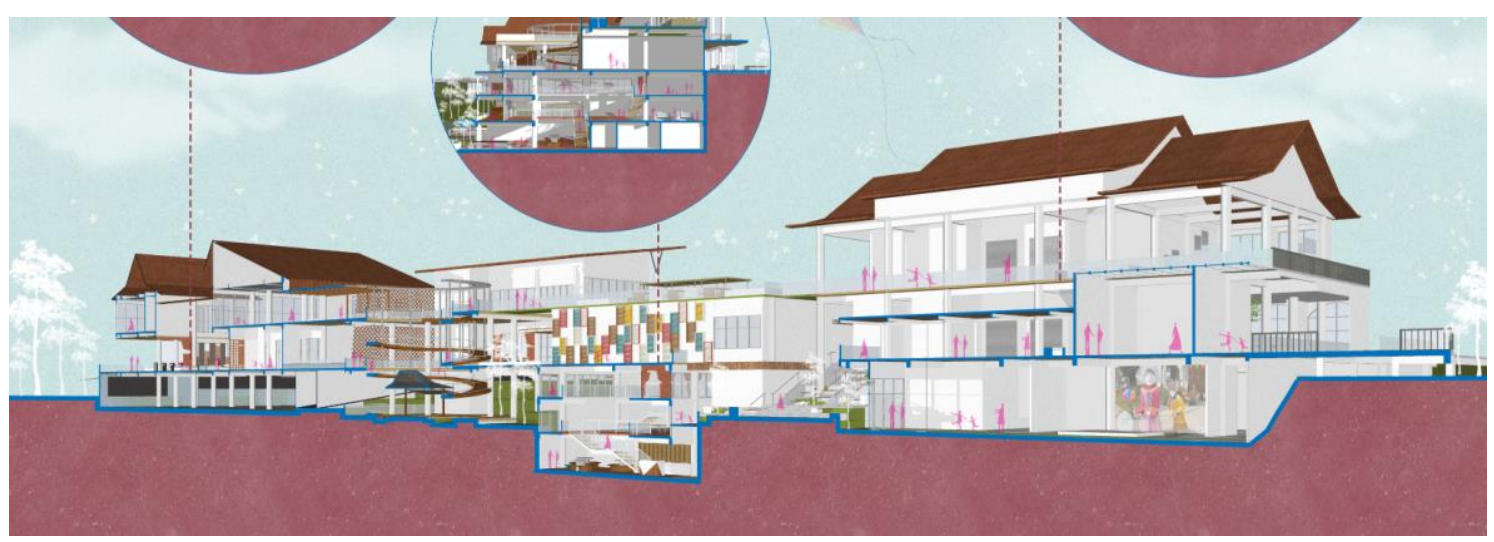

Gambar 12. Potongan Perspektif

Sumber: Penulis, 2019

Massa dibagi menjadi 3 bagian dan memiliki keterkaitan berdasarkan tema alur yang diterapkan. Pada massa pertama, dominasi diperuntukan untuk publik, karena adanya integrasi dari Stasiun Lenteng Agung, maka lebih baik disiapkan beberapa keperluan publik seperti ATM center, toilet publik, dan beberapa retail. Pada massa kedua dan ketiga terdapat zona-zona seperti edukasi, kesenian, dan permainan yang digambarkan sebagai trap sendiri.

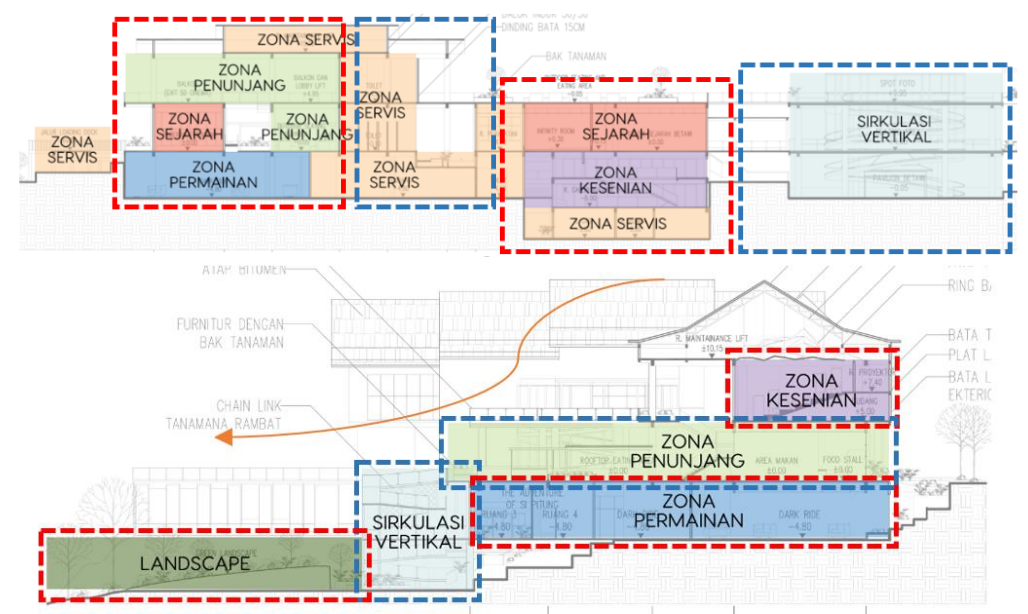

Gambar 13. Potongan Tourist Trap

Sumber: Penulis, 2019

Pada bagian zoning bagian barat bangunan, merupakan green landscape sebagai bentuk integrasi yang ada didepannya, serta panggung dan amphitheatre bila ada event atau pertunjukan. Amphitheater dirancang di antara massa bangunan, sehingga mendapatkan bayangan dari bangunan dengan pertimbangan cuaca dan iklim. 
Perancangan juga didasari dengan teknologi-teknologi dimana perilaku millenial yang sudah terbiasa hidup di jaman perkembangan teknologi yang pesat sehingga, perlu adanya penggunaan teknologi dalam perancangan, sehingga millenial dapat merasa lebih familiar dengan suasana dan lebih eksploratif dalam menjadi suatu bagian dari cerita maupun seni.

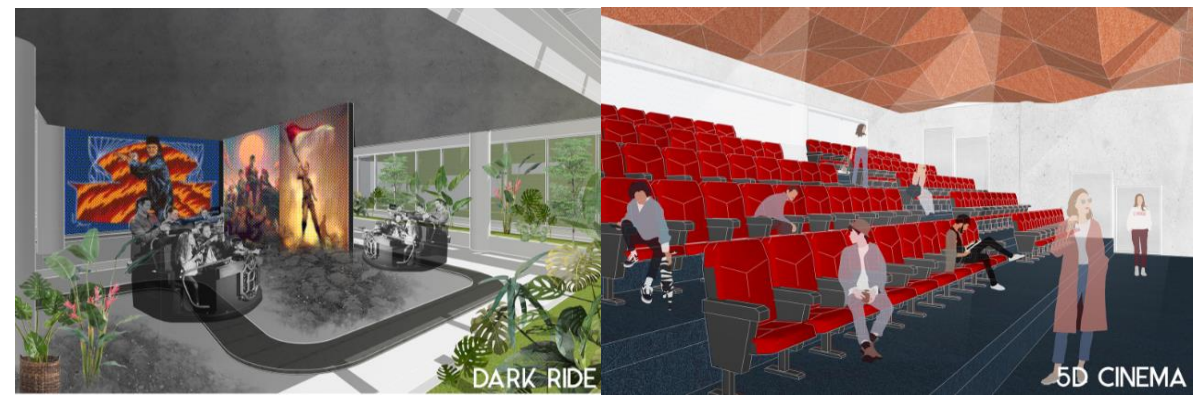

Gambar 14. Dark Ride dan 5D Cinema Sumber: Penulis, 2019

Dark ride dan 5D cinema ini adalah zona yang menggunakan teknologi seperti efek-efek dan layar interaktif serta sensor dari pengunjung. Pada permainan dark ride, pengunjung diajak masuk menggunakan kereta, dan cerita akan berjalan dengan tampilan dari layar LED yang terpasang di dinding, kemudian terdapat sensor yang mendeteksi pergerakan dari para pengujung yang sedang bermain. 5D cinema juga memberikan efek hologram dengan menggunakan kaca-mata khusus, sehingga pengujung dapat merasakan secara 3D cerita dari film yang ditayangkan sehingga mendapatkan pengalaman imersif.

\section{KESIMPULAN DAN SARAN}

Penggunaan metode naratif yang membuat pengalaman ruang lebih kaya akan arti dan konten yang ingin disampaikan, penggunaan atap rumah kebaya sebagai ciri khas dari arsitektur betawi dan diterapkan melalui metode pendekatan neovernakular. Penerapan tema trap yang diterapkan dalam pembentukan massa, tapak berkontur, dan keseluruhan proyek dengan tujuan proyek dimana dapat menarik perhatian millenial dan menyalurkan wisatawan, sehingga kawasan Jakarta Selatan dapat memiliki kawasan pariwisata terpusat. Selain itu, dengan adanya perancangan perangkap turis dengan pengalaman budaya ini dapat menjadi upaya untuk meningkatkan minat dan pengetahuan generasi millenial terhadap budaya betawi dapat dilestarikan dan tetap menjadi identitas dari Kota Jakarta.

\section{REFERENSI}

Coates, N. (2012). Narrative Architecture. United Kingdom: Wiley

Hassa, A. (2016). Augmented Reality Application for Visitor Experience. Australia: Monash University

Ho, P. dan John A. (2009), Theme Park, diunduh pada 16 Mei <

https://www.edb.gov.hk/attachment/en/curriculum-development/kla/pshe/referencesand resources/tourism/Theme_Park_en.pdf;

Mine, M. R. (2018). Projection-Based Augmented Reality in Disney Theme Park, diunduh pada 28 Mei 2019, <https://www.researchgate.net/publication/235961176_Projection-

Based_Augmented_Reality_in_Disney_Theme_Parks;

Purawdi. (2016). Indonesia 2020: The Urban Middle Class Millenials. Jakarta: PT. Alvara Strategi Indonesia

Yaxley, N. (2013). A Design Narrative: Design Intent, Persception, Experience and a Structural Logic of Space

<https://www.academia.edu/12023528/A_Design_Narrative_Design_Intent_Perception_Ex perience_and_a_Structural_Logic_of_Space; 
